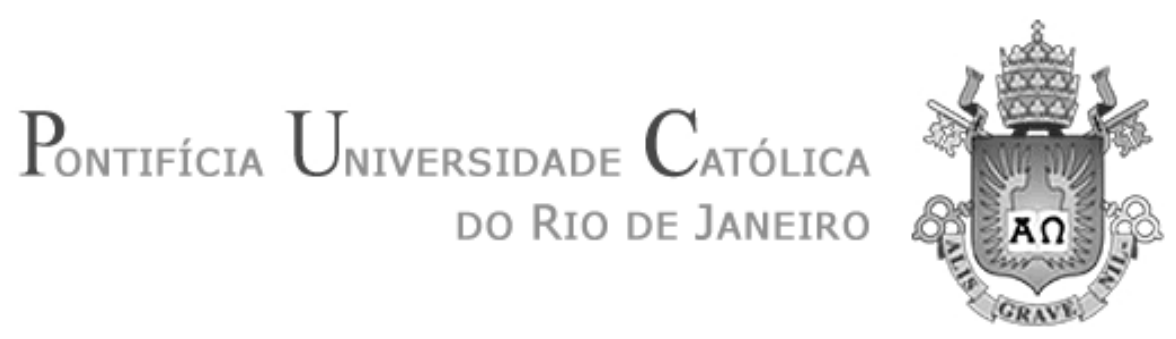

Manoel Bernardino de Santana Filho

\author{
Palavra Evento e Práxis Libertadora \\ A Eclesiologia de Karl Barth e sua Contribuição \\ Para a Teologia Latino-americana
}

Tese de Doutorado

Tese apresentada ao programa de Pós-Graduação em Teologia, do Centro de Teologia e Ciências Humanas da Pontifícia Universidade Católica do Rio de Janeiro como requisito parcial para obtenção do título de Doutor em Teologia.

Orientadora: Prof ${ }^{a}$. Ana Maria de Azeredo Lopes Tepedino 


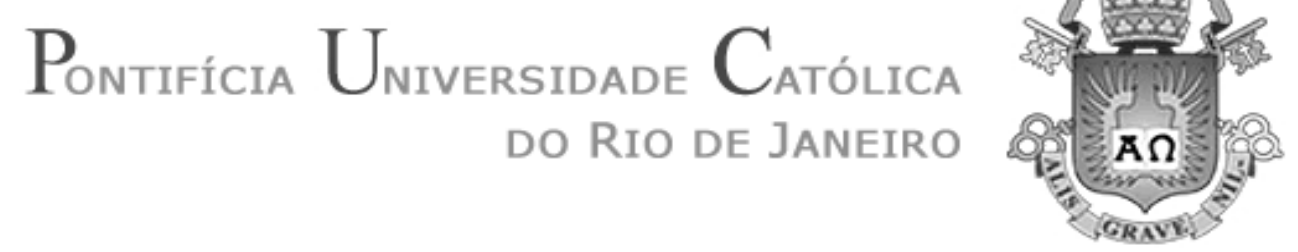

Manoel Bernardino de Santana Filho

\title{
Palavra Evento e Práxis Libertadora: a eclesiologia de Karl Barth e sua Contribuição Para a Teologia Latino-americana
}

Tese apresentada como requisito parcial para obtenção do grau de Doutor pelo Programa de Pós-Graduação em Teologia do Centro de Teologia e Ciências Humanas da PUC-Rio. Aprovada pela comissão examinadora abaixo assinada.

\author{
Profa. Ana Maria de A. L. Tepedino \\ Orientadora \\ Departamento de Teologia - PUC-Rio \\ Profa . Tereza Maria Pompéia Cavalcanti \\ Departamento de Teologia PUC-Rio
}

Prof. Paulo Cezar Costa

Departamento de Teologia PUC-Rio

Prof. Alessandro Rodrigues Rocha

FATERJ

Prof. Claudio de Oliveira Ribeiro
UMESP

Profa. Denise Berruezo Portinari

Coordenadora Setorial de Pós-Graduação e Pesquisa do Centro

de Teologia e Ciências Humanas - PUC-Rio

Rio de Janeiro, 16 de março de 2012 
Todos os direitos reservados. É proibida a reprodução total ou parcial do trabalho sem autorização da Universidade, do autor e da orientadora.

\section{Manoel Bernardino de Santana Filho}

Graduou-se em teologia pelo Seminário Teológico Congregacional do Rio de Janeiro em 1982 e em Filosofia pela Universidade do Estado do Rio de Janeiro em 1990. É Mestre em Teologia pela PUC-Rio (2007). Tem artigos publicados em livros e revista da Associação de Seminários Teológicos Evangélicos, na Revista da Faculdade Teológica Evangélica do Rio de Janeiro (Faterj), capítulo de livro publicado pelas Edições Paulinas (2007) e livro biográfico lançado em 2006. É Vice-Presidente da Associação de Seminários Teológicos Evangélicos (Aste), membro da Fraternidade Teológica Latino-americana e da Academia Evangélica de Letras do Brasil.

Ficha Catalográfica

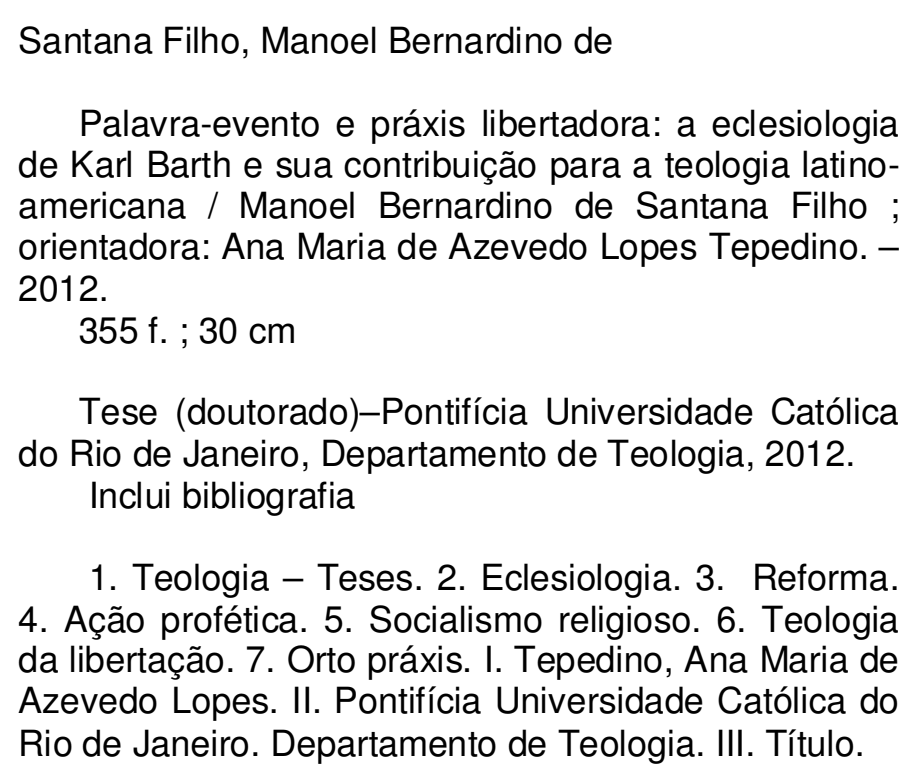
de Karl Barth e sua contribuição para a teologia latinoamericana / Manoel Bernardino de Santana Filho ; orientadora: Ana Maria de Azevedo Lopes Tepedino. 2012.

355 f. ; $30 \mathrm{~cm}$

Tese (doutorado)-Pontifícia Universidade Católica do Rio de Janeiro, Departamento de Teologia, 2012. Inclui bibliografia

1. Teologia - Teses. 2. Eclesiologia. 3. Reforma. 4. Ação profética. 5. Socialismo religioso. 6. Teologia da libertação. 7. Orto práxis. I. Tepedino, Ana Maria de Azevedo Lopes. II. Pontifícia Universidade Católica do Rio de Janeiro. Departamento de Teologia. III. Título.

CDD: 200 


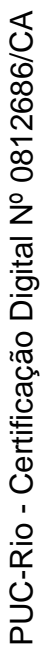

À

Rubem Ximenes Sobrinho 


\section{Agradecimentos}

Aos professores e professoras do Departamento de Teologia da PUC-Rio, pelo companheirismo, respeito e amizade.

À minha orientadora, professora Ana Maria Tepedino, pelo apoio, encorajamento e amizade. Sou grato por todos estes anos em que me assistiu na gestação desta tese.

À Igreja Congregacional de Vicente de Carvalho pela compreensão em minhas ausências.

À PUC-Rio, a Capes e à Faperj, por criarem condições de trabalho que tornaram possível a pesquisa.

À minha família, Denize, Gustavo, Manoela e Priscila.

Aos meus irmãos, Jessé, Jonas, Isac e Azenete.

A Nilzo Martins de Oliveira que me apresentou à PUC-Rio.

Aos meus alunos e alunas do Seminário Teológico Congregacional do Rio de Janeiro e do Seminário Teológico Congregacional do Estado do Rio de Janeiro (Alcântara, SG).

À Rosangela Santos Barreto Gonçalves e Viviane Martins pela revisão do texto e preparação das cópias. 


\section{Resumo}

Santana Filho, Manoel Bernardino; Tepedino, Ana Maria. Palavra Evento e Práxis Libertadora; a eclesiologia de Karl Barth e sua contribuição para a teologia latino-americana. Rio de Janeiro, 2012. 355p. Tese de Doutorado - Departamento de Teologia, Pontifícia Universidade Católica do Rio de Janeiro.

A teologia de Karl Barth se caracteriza por afirmar o caráter fenomenal da manifestação de Deus na história. Ela só é verdadeiramente Palavra de Deus quando toca existencialmente o ser humano. É a palavra que acontece a cada instante levando o indivíduo a uma crise e consequentemente a uma tomada de posição. Ela acontece plenamente em Jesus Cristo, Aquele que propicia o encontro entre o eterno e o temporal. Neste trabalho o autor procurará mostrar a influência desta teologia nos teólogos latino-americanos especialmente naqueles pertencentes à Teologia da Libertação. O conceito barthiano de palavra como evento encontra sua correspondência na práxis histórica que privilegia a ação antes que a teoria. Barth trabalha com o método prática $>$ teoria $>$ prática. Ele parte da experiência e faz da teologia um segundo momento na prática eclesial. A partir daí retorna para a prática. Esse método encontra-se presente na metodologia teológica da América Latina.

\section{Palavras-Chave}

Eclesiologia; Reforma; Ação Profética; Socialismo Religioso; Teologia da Libertação; Orto práxis. 


\section{Abstract}

Santana Filho, Manoel Bernardino; Tepedino, Ana Maria. (Advisor). Event Word and Liberation Praxis: Karl Barth's ecclesiology and his contribution to latin-american theology. Rio de Janeiro, 2012. 355p. Doctoral Thesis - Departamento de Teologia, Pontifícia Universidade Católica do Rio de Janeiro.

Karl Barth's theology is characterized by the affirmation of the phenomenal character of the manifestation of God in history. It is only truly the Word of God when it touches the human being existentially. It's the word that happens at each moment taking the individual to a crisis and, consequently, to take a position. It happens fully in Jesus Christ, the One who provides the meeting of the eternal and the temporal. In this work the author will try to show the influence of this theology in the Latin-American theologians, especially in those belonging to the Theology of Liberation. The barthian concept of the word as an event finds its equivalent in the historical praxis that gives privilege to the action over the theory. Barth works with method practice $>$ theory $>$ practice, starting from the experience and making theology a second moment in ecclesial practice, returning to practice from this point. This method is present in Latin America's theological methodology.

\section{Keywords}

Ecclesiology; Reformation; Prophetic's Action; Religious Socialism; Liberation Theology; Orthopraxis. 


\section{Sumário}

\section{PRIMEIRA PARTE}

1. Introdução

12

2. A Teologia de Karl Barth: Antecedentes 21

2.1. A Teologia da Reforma 22

2.1.1. Martinho Lutero 23

2.1.2. João Calvino 25

2.2. A Época da Ortodoxia 30

2.3. O lluminismo e sua Influência na Teologia Reformada 34

3. Igreja e Socialismo $\quad 37$

3.1. A influência da teologia liberal 39

3.1.1. Friedrich Schleiermacher 44

3.1.2. Adolf von Harnack 52

3.1.3. Sören Kierkegaard 54

3.2. A teologia dialética 56

3.3. Socialismo em Safenwill 59

3.4. Socialismo Religioso 62

3.4.1. Werner Sombart 64

3.4.2. Johann Christoph Blumhardt 66

3.4.3. Christoph Friedrich Blumhardt 68

3.4.4. Jesus ist Singer: a Influência dos Blumhardts 71

3.5. Fim do Liberalismo 74

3.6. Atuação Política no III Reich 78

3.7. Teologia e Socialismo 90

4. Igreja, Comunidade de Jesus Cristo 102 
4.1. Interpretação Bíblica 103

4.2. Hermenêutica Libertadora 104

4.3. Deus como Problema Hermenêutico 111

4.4. A Bíblia na Comunidade 114

4.5. Wilhelm Herrmann 117

4.6. Igreja entre Tempo e Eternidade 118

4.7. Igreja de Esaú e Igreja de Jacó 121

4.8. O Ser da lgreja 122

4.9. Igreja como Realidade Dinâmica 124

4.10. Igreja, Comunidade de Fé 125

4.11. Igreja e Comunidade 126

4.12. Comunidade Civil e Comunidade Cristã 130

4.13. Igreja como Arauto 133

4.14. Crítica da doutrina dos dois reinos na Teologia de Lutero 136

4.15. Communio Sanctorum 141

\section{SEGUNDA PARTE}

5. O Estatuto da Teologia Latino-americana 151

5.1. Uma Nova Teologia 151

5.2. Libertação como Paradigma 166

5.3. Apropriação do Marxismo pela Teologia 170

5.4. Uma Nova Hermenêutica 175

5.5. Um Novo Sistema Teológico Global 181

6. Reminiscências de Karl Barth na América Latina 187

6.1. José Míguez Bonino 187

6.2. Richard Shaull 203

6.3. Gustavo Gutierrez 230

6.4. Elsa Tamez 248 
7. Práxis Libertadora e Ação Profética: Barth na América Latina 275

7.1. Igreja e Sociedade na América Latina 275

7.2. Igreja e Mundo 282

7.2.1. Salvação e Justificação 284

7.2.2. Salvação e Santificação 286

7.2.3. Salvação e Vocação 287

7.3. Antropologia de Comunhão e Libertação 298

7.4. Comunhão e Serviço 302

7.5. Ação Profética e Práxis Libertadora em diálogo 306

8. Conclusão 317

9. Referências Bibliográficas 327 


\title{
Siglas
}

\author{
AL - América Latina \\ BJ - Bíblia de Jerusalém \\ CD - Church Dogmatics \\ CEB - Confederação Evangélica do Brasil \\ CELA - Conferência Evangélica Latino-americana \\ DC - Deutsche Christen \\ DEK - Deutsche Evangelische Kirche \\ FET - Faculdade Evangélica de Teologia \\ ISAL - Igreja e Sociedade na América Latina \\ KD - Kirchliche Dogmatik \\ JMB - José Miguel Bonino \\ JSC - José Severino Croatto \\ NS - Nacional Socialismo \\ RA - Bíblia versão Revista e Atualizada da SBB \\ R1 - Der Römerbrief (Erste Farsung, 1919) \\ R2 - Der Römerbrief (1922) \\ SBB - Sociedade Bíblica do Brasil \\ SPC - Seminário Presbiteriano de Campinas \\ STPISP - Seminário Teológico Presbiteriano Independente de São Paulo \\ TdL - Teologia da Libertação
}

